\title{
Gag:267-274 Peptide Vaccine
}

National Cancer Institute

\section{Source}

National Cancer Institute. Gag:267-274 Peptide Vaccine. NCI Thesaurus. Code C102982.

A peptide vaccine containing the amino acids 267 through 274 of the human immunodeficiency virus type 1 (HIV-1) gag core protein (gag:267-274), with potential immunostimulating activity. Upon vaccination, the immune system may exert a potent cytotoxic T-lymphocyte (CTL) response against the xenoantigen gag:267-274 and produces pro-inflammatory cytokines. The concomitant administration of a cancer peptide vaccine may benefit from an already activated immune system and may augment an immune response against the administered tumor associated antigen(s). Gag:267-274 peptide is highly immunogenic and may potentially be used as a cancer immunoadjuvant. 